\title{
1 Sex Differences in Behavioral Responses during a Conditioned Flight Paradigm
}

2 Chandrashekhar D. Borkar ${ }^{1,2}$, Mariia Dorofeikova ${ }^{1,2}$, Quan-Son Eric Le $e^{1,2,3}$, Rithvik Vutukuri²,3,

3 Catherine $\mathrm{Vo}^{2,3}$, Daniel Hereford ${ }^{1,2,3}$, Alexis Resendez ${ }^{1,2}$, Samhita Basavanhalli2,3, Natalia

4 Sifnugel ${ }^{1,2,3}$, Jonathan P. Fadok ${ }^{1,2,3^{*}}$

5 Author Affiliations: ${ }^{1}$ Department of Psychology, Tulane University, New Orleans, Louisiana 70118,

6

7

8

9

10

11

12

13

14

15

16

17

\section{USA}

2Tulane Brain Institute, Tulane University, New Orleans, Louisiana 70118, USA

${ }^{3}$ Program in Neuroscience, Tulane University, New Orleans, Louisiana 70118, USA

*Corresponding author: Jonathan P. Fadok

Email: jfadok@tulane.edu

Tulane Brain Institute

Tulane University \#1345

6823 St. Charles Ave.

New Orleans, LA 70118-5698 
Highlights:

- Male and female mice do not differ in conditioned flight behavior.

- Female mice exhibit more freezing behavior.

- Rearing, self-grooming, and tail rattling behavior changes across days.

- Male mice exhibit more rearing and grooming behavior.

- Female mice exhibit more tail rattling behavior.

\section{Abstract}

Females exhibit greater susceptibility to trauma- and stress-related disorders compared to males; therefore, it is imperative to study sex differences in the mode and magnitude of defensive responses in the face of threat. To test for sex differences in defensive behavior, we used a modified Pavlovian fear conditioning paradigm that elicits clear transitions between freezing and flight behaviors within individual subjects. Female mice subjected to this paradigm exhibited higher percentages of freezing behavior compared to males, especially during the intertrial interval period. Female mice also exhibited more cued freezing in response to the conditioned stimuli in the last block of extinction training. Furthermore, there were sex differences in the expression of other adaptive behaviors during fear conditioning. Assaying rearing, grooming, and tail rattling behaviors during the conditioned flight paradigm yielded measurable differences across sessions and between males and females. Overall, these results provide insight into sexdependent alterations in mouse behavior induced by fear conditioning.

Keywords: sex differences, defensive behavior, fear conditioning 


\section{Introduction}

Women have an approximately twofold higher risk of developing post-traumatic stress disorder (PTSD) compared to men [1,2], and they also display greater vulnerability to developing anxiety-related disorders [3]. Maladaptive behavioral responses to threats are associated with trauma- and anxiety-related disorders, making it imperative to study sex differences in the mode and magnitude of defensive behavior.

Pavlovian fear conditioning is a powerful model system that has provided tremendous insight into the neural mechanisms underlying fear-related learning and memory, mechanisms that are likely dysregulated in PTSD and anxiety disorders. Although a majority of research employing Pavlovian fear conditioning has used exclusively male subjects, some studies have explored sex differences in fear-related learning and memory. For example, female mice have been shown to generalize contextual fear more than males [4], while other studies have found that female mice and rats have impaired cued fear extinction [5-7]. Although these investigations provide insight into sex differences in generalization and extinction learning, they have often categorized freezing as the sole measurable index of fear.

According to the predatory imminence theory, different defensive behaviors are elicited depending on threat intensity, proximity, and context [8]. Based on this theory, we recently developed a modified Pavlovian conditioning paradigm that elicits clear transitions between conditioned freezing and flight behavior within individual subjects [9]. Therein, the conditioned flight paradigm was used to reveal important amygdala circuitry for the selection of defensive behavior; however, it utilized exclusively male mice. Therefore, we aimed to test the extent of sex differences in the conditioned flight paradigm. Additionally, we set out to examine sex differences in other adaptive behavioral changes in response to fear conditioning. 


\section{Materials and Methods}

66

67

68

69

70

71

72

73

74

75

76

77

78

79

80

81

82

83

84

85

86

87

88

89

\subsection{Animals}

Adult male and female C57/BL6J mice (Jackson laboratory, USA) aged 3-5 months were used for the present study. All mice were individually housed on a $12 \mathrm{~h}$ light/dark cycle throughout the study with ad libitum access to food and water. Behavioral experiments were performed during the light cycle. All animal procedures were performed in accordance with institutional guidelines and were approved by the Institutional Animal Care \& Use Committee of Tulane University.

\subsection{Conditioned flight paradigm}

Two different contexts were used for the conditioned flight paradigm. Context A consisted of a clear cylindrical chamber with a smooth floor, while Context B consisted of a clear square enclosure with an electrical grid floor (Med Associates, Inc.) used to deliver alternating current footshocks (ENV-414S, Med Associates Inc.). These two chambers were cleaned with $1 \%$ acetic acid and $70 \%$ ethanol, respectively. An overhead speaker (ENV-224AM, Med Associates, Inc.) was mounted above the chambers to deliver auditory stimuli at $75 \mathrm{~dB}$. A programmable audio generator (ANL-926, Med Associates, Inc.) generated auditory stimuli. Behavioral protocols were generated using MedPC software (Med Associates, Inc.) to control auditory stimuli and shock via TTL pulses with high temporal precision.

The study sessions were conducted over a period of 4 days. Day 1 (pre-exposure) included a 3 min baseline period followed by 4 presentations of a serial compound stimulus (SCS) of $20 \mathrm{sec}$ total duration in context A, with an $80 \mathrm{sec}$ average pseudorandom intertrial interval (ITI) (range $60-100 \mathrm{sec}$ ). The SCS was a serial presentation of $10 \mathrm{sec}$ pure tone $(500 \mathrm{~ms}, 7.5 \mathrm{kHz}$ pips at $1 \mathrm{~Hz}$ ) and $10 \mathrm{sec}$ white noise $(500 \mathrm{~ms}$ pips at $1 \mathrm{~Hz}$ ). The white noise was random and composed of frequencies from 1-20,000 Hz. The pre-exposure session lasted for 590 sec in total. On Day 2 and Day 3 (conditioning), mice were subjected to Context B and, after a 3 min baseline period, presented with five pairings of the SCS co-terminating with a $1 \mathrm{sec}, 0.9 \mathrm{~mA}$ AC footshock, 
with a $120 \mathrm{sec}$ average pseudorandom ITI (range 90-150 sec). Each conditioning session lasted

91 for $820 \mathrm{sec}$ in total. Day 4 consisted of the extinction session, also conducted in Context B.

92 Following a $3 \mathrm{~min}$ baseline period, mice were presented with 16 trials of the SCS without

93 footshock, with a $90 \mathrm{sec}$ average pseudorandom ITI range (60-120 sec) spread over a total period

94 of $1910 \mathrm{sec}$. This paradigm was also described in detail in [9].

95

96

97

98

99

100

101

102

103

104

105

106

107

108

109

110

111 112 analysis of behavior.

113

\subsection{Statistical Analysis}

\subsection{Quantification of behavior}

During the study, subjects were recorded and analyzed using Cineplex software (Plexon). Contour tracking ensured reliable data on relative position, while a central computer synced event markers to their real-time occurrences (Cineplex Studio, Plexon). Videos were scored for freezing behavior by an observer blind to the experiment with a frame-by-frame analysis of pixel changes (Cineplex Editor, Plexon). By determining a calibration coefficient using the chambers' known size and the camera's pixel dimensions, speed $(\mathrm{cm} / \mathrm{sec})$ was extracted using the animal's center of gravity. Jumping escape behaviors were scored manually from video files. Flight score was calculated by dividing the average speed during each CS by the average speed during the 10 sec pre-CS (baseline) and then adding 1 point for each escape jump (speed $\mathrm{Cs}_{\mathrm{C}} / \mathrm{speed}_{\mathrm{BL}}+$ \# of jumps). A flight score of 1 therefore indicates no change in flight behavior from the pre-CS period. In addition, videos were scored for rearing, grooming intervals, and tail rattling behaviors (Cineplex Editor, Plexon). To compare these adaptive behaviors effectively between fear conditioning and extinction sessions, we separated the extinction recording data into the first 820 sec (early extinction) and last $820 \mathrm{sec}$ (late extinction) periods in order to better detail behavioral transitions. We excluded two female mice from the analysis on Days 3 and 4 because they jumped out of the conditioning context in response to the white noise stimulus on Day 3, precluding an accurate 

checked for normal distribution using the Shapiro-Wilk normality test $(\alpha=0.05)$, and the appropriate parametric/non-parametric test for significance was run. No statistical methods were used to predetermine sample size.

\section{Results}

\subsection{Comparison of male and female mice in the conditioned flight paradigm}

We used a four-day conditioned flight paradigm as previously described (Figure 1; [9]).

On Day 1, mice freely explored a novel environment (Context $A$ ) and a serial compound stimulus into the conditioning context (Context B) and presented with five pairings of the SCS co-

To analyze sex differences in conditioned freezing and flight behavior, we conditioned 10 male and 10 female mice in the flight paradigm. Both male and female mice developed robust freezing responses to the tone stimulus as well as robust flight responses to the white noise stimulus over the course of conditioning (Figure 2a-b). Consistent with our previous results [9],

131 there was a significant cue $X$ trial effect on flight behavior (Figure 2a; mixed-effects analysis, $\left.132 \mathrm{~F}_{(1.849,30.43)}=4.3, \mathrm{p}<0.05\right)$. There was also a significant cue $\mathrm{X}$ trial effect on freezing behavior in both males and females (Figure $\mathbf{2 b}$; mixed-effects analysis, $F_{(6.134,101.0)}=18.48, p<0.0001$ ). 
average number of jumps: 5 for male and female; unpaired $t$ test) nor in response to shock (average number of jumps: 3 for male and female, unpaired t test, $p=0.97$ ). Flight scores were significantly higher during the white noise for both males and females (Figure 2e; two-way repeated-measures ANOVA, effect of cue, $\left.F_{(1,16)}=21.18, p<0.001\right)$, and there was no significant sex difference in white noise-elicited flight (flight scores: 13.4 male and 12.1 female; Mann Whitney test, $p=0.90)$. versus $51 \%$; unpaired t test, $p=0.16)$ and elevated freezing during the tone period $(60 \%$ versus $68 \%$, unpaired t test, $p=0.46$ ). Males and females exhibited reduced freezing during the white noise stimulus $(6.13 \%$ male, $16.25 \%$ female), consistent with the behavioral switch to flight. Freezing in female mice was significantly higher than in males during the white noise period (Mann-Whitney test, $\mathrm{p}<0.01$ ).

On Day 4, mice underwent extinction training in the conditioning context. Flight behavior underwent rapid extinction in male and female mice (Figure $\mathbf{2 g}$ ). During extinction training, flight responses were elicited specifically by the white noise stimulus and flight only occurred during 153 the early extinction trials in both males and females (Figure $\mathbf{2} \mathbf{h}, \mathbf{i}$ ). There was no significant difference in flight scores between males and females (flight scores during first four trials: 4.63 male, 5.16 female; Mann Whitney test, $p=0.23$ ). Freezing behavior also changed over the course of extinction training (Figure $\mathbf{2 j}$ ). There was significant within-session extinction in tone-induced 157 freezing in male and female mice (Figure 2k; first four trials versus last four trials; Paired t test, $p<0.001$ male, $p<0.05$ female). Female mice had higher levels of freezing to the tone stimulus in

159 the last bin of extinction trials compared to males, but this did not reach statistical significance 160 (18.9\% male, $32.6 \%$ female, unpaired $t$ test, $p=0.13)$. Freezing during the white noise period did 161 not change during the extinction session for male mice (34.9\% versus $30.3 \%$; Paired $t$ test, 
$162 \mathrm{p}=0.68$ ); however, there was a significant increase in freezing to the white noise in female mice

163 (Figure 2l; 1st four trials versus last four trial; 21.7\% versus 55.6\%; Paired t test, $p<0.01$ ).

164

\subsection{Total freezing levels are higher in female mice}

We next investigated sex differences in other dynamics of freezing and flight such as total duration, number of bouts, and duration per bout. On Day 3, there was no significant difference between males and females in the total duration of flight (Figure 3a; 12.2 sec male versus 14.2 sec female, unpaired t test, $p=0.54$ ), the number of flight bouts (Figure $3 \mathbf{b} ; 7.4$ male versus 7.8 female, unpaired t test, $p=0.82$ ), or the duration of flight bouts (Figure $3 \mathrm{c} ; 1.7 \mathrm{sec}$ male versus $1.8 \mathrm{sec}$ female, unpaired t test, $p=0.44)$. Interestingly, females had significantly higher total freezing duration on Day 3 (Figure 3d; $297.4 \mathrm{sec}$ male versus $411.2 \mathrm{sec}$ female, unpaired t test, $p<0.05)$. Although there was no significant difference in the number of freezing bouts (Figure 3e; 67.4 male versus 61.8 female, unpaired t test, $p=0.53$ ), the average duration of individual freezing bouts was significantly higher in females (Figure 3f; $4.5 \mathrm{sec}$ males versus $6.8 \mathrm{sec}$ females, unpaired t test, $p<0.05)$. The differences in total session freezing behavior between males and females can be attributed to significant differences in the levels of freezing during the ITI. Females expressed significantly elevated freezing during the ITI, both in total ITI freezing (Figure 3g; 264.6 sec male versus $372.7 \mathrm{sec}$ female, unpaired test, $\mathrm{p}<0.05$ ) and in the duration of individual ITI freezing bouts (Figure $3 \mathrm{~h} ; 4.4 \mathrm{sec}$ males versus $6.6 \mathrm{sec}$ female, unpaired t test, $\mathrm{p}<0.05$ ).

\subsection{Changes in other adaptive behaviors during conditioning}

In addition to flight and freezing, we quantified a number of other adaptive behaviors expressed during the conditioned flight paradigm. These included rearing, grooming, tail rattling, and general exploration. To demonstrate how these behaviors changed over trials, we generated mouse ethograms (Figure 4) to demonstrate behavioral dynamics over the course of conditioning. 
Rearing behavior changed significantly over the course of conditioning (Figure 5a; mixedeffects analysis, effect of session $\left.\mathrm{F}_{(2.119,34.97)}=152.8, \mathrm{p}<0.0001\right)$. Rearing behavior significantly decreased in male and female mice from Day 1 to Day 3 (Tukey's multiple comparisons test; Day 1 versus Day 2, $p<0.0001$; Day 2 versus Day 3, $p<0.0001)$. There was a significant increase in rearing during the extinction session compared to Day 3 (Tukey's multiple comparisons test; Day 3 versus Day 4-early, $p<0.001$; Day 3 versus Day 4-late $p<0.0001)$. Interestingly, males reared significantly more than females on Day 3 (Figure $\mathbf{5 d}$; Mann-Whitney test, $\mathrm{p}<0.05$ ).

(Figure 5b; mixed-effects analysis, effect of session $\left.F_{(1.853,30.58)}=16.82, p<0.0001\right)$. Grooming decreased significantly from Day 1 to Day 2 (Tukey's multiple comparisons test; $p<0.001$ ). Grooming increased over the course of the extinction session (Tukey's multiple comparisons test; levels that were significantly higher than those of the pre-conditioning session (Tukey's multiple comparisons test; Day 1 versus Day 4-late, $p<0.05)$. Just as with rearing, males groomed significantly more than females on Day 3 (Figure 5e; Mann-Whitney test, $p<0.05$ ).

Neither male nor female mice exhibited tail rattling behavior during the preconditioning session on Day 1 (Figure 5c). Occurrences of tail rattling increased for males and females during conditioning on Day 2 and remained elevated throughout Days 3 and 4 (Figure 5c; mixed-effects analysis, effect of session $\mathrm{F}_{(2.090,34.48)}=9.222, \mathrm{p}<0.001$; Tukey's multiple comparisons test, Day 1 versus Day 2, $p<0.01$; Day 1 versus Day 3, $p<0.001$; Day 1 versus Day 4-early, $p<0.05$; Day 1 
Using a fear conditioning paradigm that elicits both freezing and flight responses, we analyzed sex differences in defensive behavior (Figures 1-3). We found that male and female

211 mice do not differ in conditioned flight behavior, yet freezing behavior is significantly greater in

212 females (Figures 2, 3). Specifically, we found that females freeze more overall (Figure 3d,f) on

213 Day 3, and that this increase is attributable to increased freezing during the white noise period

214 (Figure 2f), with the greatest difference during the ITI (Figure $\mathbf{3 g} \mathbf{\mathbf { i }}$ ). There were also sex

215 differences in other forms of adaptive behavior as mice underwent conditioning. By constructing

216 ethograms, we were able to visualize the dynamics of these changes on a trial-by-trial basis

217 (Figure 4). Rearing, grooming, and tail rattling behaviors all changed across sessions and there were sex differences in the expression of all three of these adaptive behaviors (Figure 5). behavior $[10,11]$. These same studies found that female rats freeze less than males despite 222 having a greater locomotor response to the shock [10]. Other studies also report lower contextual 223 freezing in female rats [12-14], but similar levels of freezing to the auditory CS [13]. Interestingly, 224 rats that engage in darting behavior express enhanced retention of extinction memory [11]. In this 225 current study, we found that female mice freeze more than male mice on Day 3 in response to 226 white noise and during the ITI period (Figures 2 and 3). Female mice also freeze significantly 227 more in response to tone and white noise in the late extinction session (Figure 2). This is 228 consistent with previous studies reporting impaired tone extinction memory in female mice and 229 female rats [5-7]. Other studies in mice report that females are more likely to show generalized 230 contextual fear [4]. Although results from different studies may seem disparate, it is important to 231 appreciate that defensive behavior repertoires and situational response selection are likely to vary by species, strain, and sex. Careful behavioral analysis is therefore imperative for determining 
the specific strengths of each model for understanding the dysfunctions characteristic to PTSD and anxiety disorders [15-18].

Stress has profound effects on behavior, yet there is little knowledge of the sex differences in behavioral expression impacted by fear conditioning. Therefore, we examined the effects of conditioning and extinction training on rearing, grooming, and tail rattling in the mice subjected to the conditioned flight paradigm. Rearing is an index of arousal and general exploratory behavior in response to novelty $[19,20]$, and this behavior changes during commonly used tests of anxietylike behavior [21-23]. Our results show that both male and female mice decrease rearing behavior during the conditioned flight paradigm, and although rearing does not return to pre-conditioning levels, there is a significant return of rearing behavior during extinction training (Figure 5a). The severe reduction in rearing activity could be the result of the stress induced during conditioning, which might be reduced during fear extinction [21,23]. Interestingly, male mice rear more than females on Day 3 of the flight paradigm, which suggests that they might be more resilient to the deleterious effects of stress on behavior.

Grooming behavior is a self-maintenance behavior that is often used for stress reduction [24]. In response to stress, self-grooming behavior follows an inverted-U shaped curve, occurring spontaneously at low arousal levels, increasing during moderate arousal, and deteriorating during high-stress conditions that elicit freezing or flight responses $[19,24,25]$. Here, we find that grooming behavior significantly decreases during the conditioning phase of the flight paradigm in both male and female mice, while grooming eventually exceeds baseline levels by the end of the extinction session (Figure 5b). Interestingly, male mice groom more than females on Day 3, suggesting that the stress of undergoing fear conditioning differentially affects the subject according to sex. Reduced grooming in female mice may be suggestive of impaired stress coping strategies in females exposed to threatening situations. 
Tail rattling is an aggressive defensive response elicited during social confrontation or in response to threat [26-28]. During the conditioned flight paradigm, tail rattling increases on the first day of conditioning and decreases during extinction for both male and female mice (Figure 5c). We also find that female mice exhibit significantly greater numbers of tail rattles than males on the first day of conditioning. Because tail rattling is elicited primarily in response to threat [28], this could have implications for understanding how trauma differentially affects expression of defensive aggression in males and females. For example, this may have translational relevance for understanding aspects of the hypervigilance response observed in patients with PTSD $[17,18]$. Our findings point to differential regulation of defensive adaptive behaviors between males and females. Subsequent studies can build upon these findings to reveal sex differences in the circuits controlling bodily responses to stress, anxiety, and fear. For example, our previous work in male mice demonstrated that central amygdala circuits are essential for switching between freezing and flight responses [9]. That study and others have shown that somatostatin-expressing neurons of the central amygdala are necessary for freezing behavior [9,29], whereas neurons expressing corticotropin-releasing factor are necessary for flight [9]. Because females express higher levels of freezing than males, future studies should investigate potential sex differences in the function of central amygdala neuronal networks, especially in light of recent work that has described sex differences in other nuclei important for defensive behavior [30,31].

\section{Acknowledgements}

Conceptualization, C.D.B. and J.P.F.; Methodology, C.D.B. and J.P.F.; Formal Analysis, C.D.B., M.D., Q.E.L., R.V., C.V., D.H., A.R., S.B., N.S.; Investigation, C.D.B. and Q.E.L.; Resources, J.P.F.; Writing - Original Draft, C.D.B., M.D., and J.P.F.; Visualization, C.D.B., D.H., and J.P.F.; Supervision, J.P.F.; Project Administration, C.D.B. and J.P.F.; Funding Acquisition, J.P.F. We 
bioRxiv preprint doi: https://doi.org/10.1101/2019.12.20 885038; this version posted December 23, 2019. The copyright holder for this preprint (which was not certified by peer review) is the author/funder, who has granted bioRxiv a license to display the preprint in perpetuity. It is made available under aCC-BY-NC-ND 4.0 International license.

281 thank all authors for their thoughtful comments on the manuscript. This work was supported by a

282 Louisiana Board of Regents Research Competitiveness Subprogram award (104A-18).

283 


\section{References}

285

286

287

288

289

290

291

292

293

294

295

296

297

298

299

300

301

302

303

304

305

306

307

308

309

310

311

312

313

314

315

316

317

318

319

320

321

322

[1] Breslau N. The epidemiology of trauma, PTSD, and other posttrauma disorders. Trauma Violence Abuse. 2009;10(3):198-210. https://doi.org/10.1177/1524838009334448.

[2] Kessler RC, Sonnega A, Bromet E, Hughes M, Nelson CB. Posttraumatic stress disorder in the National Comorbidity Survey. Arch Gen Psychiatry. 1995;52(12):1048-60. https://doi.org/10.1001/archpsyc.1995.03950240066012.

[3] Maeng LY, Milad MR. Sex differences in anxiety disorders: Interactions between fear, stress, and gonadal hormones. Horm Behav. 2015;76:106-17.

https://doi.org/10.1016/j.yhbeh.2015.04.002.

[4] Keiser AA, Turnbull LM, Darian MA, Feldman DE, Song I, Tronson NC. Sex differences in context fear generalization and recruitment of hippocampus and amygdala during retrieval. Neuropsychopharmacology. 2017;42(2):397-407.

https://doi.org/10.1038/npp.2016.174.

[5] Baker-Andresen D, Flavell CR, Li X, Bredy TW. Activation of BDNF signaling prevents the return of fear in female mice. Learn Mem. 2013;20(5):237-40.

https://doi.org/10.1101/lm.029520.112.

[6] Baran SE, Armstrong CE, Niren DC, Hanna JJ, Conrad CD. Chronic stress and sex differences on the recall of fear conditioning and extinction. Neurobiol Learn Mem. 2009;91(3):323-32. https://doi.org/10.1016/j.nlm.2008.11.005.

[7] Baran SE, Armstrong CE, Niren DC, Conrad CD. Prefrontal cortex lesions and sex differences in fear extinction and perseveration. Learn Mem. 2010;17(5):267-78. https://doi.org/10.1101//m.1778010.

[8] Fanselow MS, Lester LS. A functional behavioristic approach to aversively motivated behavior: Predatory imminence as a determinant of the topography of defensive behavior. In: Bolles RC, Beecher MD (Eds.), Evol. Learn., 1988: pp. 185-212. Lawrence Erlbaum Associates, Inc.

[9] Fadok JP, Krabbe S, Markovic M, Courtin J, Xu C, Massi L, Botta P, Bylund K, Müller C, Kovacevic A, Tovote $P$, Lüthi A. A competitive inhibitory circuit for selection of active and passive fear responses. Nature. 2017;542(7639):96-100.

https://doi.org/10.1038/nature21047.

[10] Colom-Lapetina J, Li AJ, Pelegrina-Perez TC, Shansky RM. Behavioral diversity across classic rodent models is sex-dependent. Front Behav Neurosci. 2019;13:45. https://doi.org/10.3389/fnbeh.2019.00045.

[11] Gruene TM, Flick K, Stefano A, Shea SD, Shansky RM. Sexually divergent expression of active and passive conditioned fear responses in rats. Elife. 2015;4.

https://doi.org/10.7554/eLife.11352.001.

[12] Gupta RR, Sen S, Diepenhorst LL, Rudick CN, Maren S. Estrogen modulates sexually dimorphic contextual fear conditioning and hippocampal long-term potentiation (LTP) in rats. Brain Res. 2001;888(2):356-65. https://doi.org/10.1016/S0006-8993(00)03116-4. 
[13] Maren S, De Oca B, Fanselow MS. Sex differences in hippocampal long-term potentiation (LTP) and Pavlovian fear conditioning in rats: positive correlation between LTP and contextual learning. Brain Res. 1994;661(1-2):25-34. https://doi.org/10.1016/0006-8993(94)91176-2.

[14] Chang YJ, Yang CH, Liang YC, Yeh CM, Huang CC, Hsu KS. Estrogen modulates sexually dimorphic contextual fear extinction in rats through estrogen receptor beta. Hippocampus. 2009;19(11):1142-50. https://doi.org/10.1002/hipo.20581.

[15] Milad MR, Pitman RK, Ellis CB, Gold AL, Shin LM, Lasko NB, Zeidan MA, Handwerger $\mathrm{K}$, Orr SP, Rauch SL. Neurobiological basis of failure to recall extinction memory in posttraumatic stress disorder. Biol Psychiatry. 2009;66(12):1075-82. https://doi.org/10.1016/j.biopsych.2009.06.026.

[16] VanElzakker MB, Dahlgren MK, Davis FC, Dubois S, Shin LM. From Pavlov to PTSD: the extinction of conditioned fear in rodents, humans, and anxiety disorders. Neurobiol Learn Mem. 2014;113:3-18. https://doi.org/10.1016/j.nlm.2013.11.014.

[17] Daskalakis NP, Yehuda R, Diamond DM. Animal models in translational studies of PTSD. Psychoneuroendocrinology. 2013;38(9):1895-911. https://doi.org/10.1016/j.psyneuen.2013.06.006.

[18] Yehuda R, LeDoux J. Response variation following trauma: a translational neuroscience approach to understanding PTSD. Neuron. 2007;56(1):19-32.

https://doi.org/10.1016/j.neuron.2007.09.006.

[19] O'Leary TP, Gunn RK, Brown RE. What are we measuring when we test strain differences in anxiety in mice? Behav Genet. 2013;43(1):34-50.

[20] Lever C, Burton S, O'Keefe J. Rearing on hind legs, environmental novelty, and the hippocampal formation. Rev Neurosci. 2006;17(1-2):111-33.

https://doi.org/10.1515/REVNEURO.2006.17.1-2.111.

[21] Arentsen T, Khalid R, Qian Y, Diaz Heijtz R. Sex-dependent alterations in motor and anxiety-like behavior of aged bacterial peptidoglycan sensing molecule 2 knockout mice. Brain Behav Immun. 2018;67:345-354. https://doi.org/10.1016/j.bbi.2017.09.014.

[22] Fraga DB, Olescowicz G, Moretti M, Siteneski A, Tavares MK, Azevedo D, Colla ARS, Rodrigues ALS. Anxiolytic effects of ascorbic acid and ketamine in mice. J Psychiatr Res. 2018;100:16-23. https://doi.org/10.1016/j.jpsychires.2018.02.006.

[23] Varga D, Herédi J, Kánvási Z, Ruszka M, Kis Z, Ono E, Iwamori N, Iwamori T, Takakuwa H, Vécsei L, Toldi J, Gellért L. Systemic L-Kynurenine sulfate administration disrupts object recognition memory, alters open field behavior and decreases c-Fos immunopositivity in C57BI/6 mice. Front Behav Neurosci. 2015;9:157. https://doi.org/10.3389/fnbeh.2015.00157.

[24] Kalueff AV, Stewart AM, Song C, Berridge KC, Graybiel AM, Fentress JC. Neurobiology of rodent self-grooming and its value for translational neuroscience. Nat Rev Neurosci. 2016;17(1):45-59. https://doi.org/10.1038/nrn.2015.8. 
[25] Denmark A, Tien D, Wong K, Chung A, Cachat J, Goodspeed J, Grimes C, Elegante M, Suciu C, Elkhayat S, Bartels B, Jackson A, Rosenberg M, Chung KM, Badani H, Kadri F, Roy S, Tan J, Gaikwad S, Stewart A, Zapolsky I, Gilder T, Kalueff AV. The effects of chronic social defeat stress on mouse self-grooming behavior and its patterning. Behav Brain Res. 2010;208(2):553-9. https://doi.org/10.1016/j.bbr.2009.12.041.

[26] St John RD. Genetic analysis of tail rattling in the mouse. Nature. 1973;241(5391):54951. https://doi.org/10.1038/241549a0.

[27] Krsiak M. Effects of drugs on behaviour of aggressive mice. Br J Pharmacol. 1979;65(3):525-33. https://doi.org/10.1111/j.1476-5381.1979.tb07861.x.

[28] Salay LD, Ishiko N, Huberman AD. A midline thalamic circuit determines reactions to visual threat. Nature. 2018;557(7704):183-189. https://doi.org/10.1038/s41586-0180078-2.

[29] Li H, Penzo MA, Taniguchi H, Kopec CD, Huang ZJ, Li B. Experience-dependent modification of a central amygdala fear circuit. Nat Neurosci. 2013;16(3):332-9. https://doi.org/10.1038/nn.3322.

[30] Blume SR, Freedberg M, Vantrease JE, Chan R, Padival M, Record MJ, DeJoseph MR, Urban JH, Rosenkranz JA3. Sex- and estrus-dependent differences in rat basolateral amygdala. J Neurosci. 2017;37(44):10567-10586. https://doi.org/10.1523/JNEUROSCI.0758-17.2017.

[31] Gruene TM, Roberts E, Thomas V, Ronzio A, Shansky RM. Sex-specific neuroanatomical correlates of fear expression in prefrontal-amygdala circuits. Biol Psychiatry. 2015;78(3):186-93. https://doi.org/10.1016/j.biopsych.2014.11.014. 
Figure 1. The conditioned flight paradigm. a) Diagram detailing the stages of the conditioned flight paradigm. Note that mice received footshocks (US) only on Days 2 and 3. b) Diagram detailing the composition of the SCS, as well as the timing of the US.

Figure 2. Sex differences in the conditioned flight paradigm. a) Average flight scores in males $(n=10)$ and females $(n=8)$ during the tone and white noise (WN) periods across Days 1-3. b) Average speed $(\mathrm{cm} / \mathrm{s})$ of males and females during the pre-SCS, tone, WN, and shock periods on Day 3. d) Comparison of number of jump escape responses in males and females during the pre-SCS, tone, WN, and shock periods on Day 3. e) Comparison of flight scores in males and females in during the tone and WN on Day 3. f) Comparison of \% freezing in males and females during the Pre-SCS, tone, and WN on Day 3. g) Average flight scores in males and females during the tone and WN on Day 4. h) Comparison of flight scores in males and females during the tone between early extinction and late extinction. i) Comparison of flight scores in males and females during the WN between early extinction and late extinction. j) Average $\%$ freezing in males and

402 females during the tone and WN on Day 4. k) Comparison of \% freezing in males and females during the tone between early extinction and late extinction. I) Comparison of \% freezing in males and females during the WN between early extinction and late extinction. The represented values are means \pm SEM. ${ }^{*} p<0.05,{ }^{* *} p<0.01,{ }^{* * *} p<0.001$.

Figure 3. Comparison of freezing behavior between sexes on Day 3. a-c) Comparison of flight scores in males and females on Day 3 in terms of total flight duration (a), number of bouts (b), and duration of flight per bout (c). d-f) Comparison of freezing in males and females on Day 3 in terms of total freezing (d), number of bouts (e), and duration of freezing per bout (f). $\mathbf{g}$-i) 410 Comparison of freezing in males and females during ITI on Day 3 in terms of total ITI freezing (g), 411 number of bouts $(\mathbf{h})$, and duration of freezing per bout (i). Bars indicate means \pm SEM. ${ }^{*} p<0.05$. 
412 Figure 4. Representative ethograms of a male and female mouse during conditioning.

413 Representative ethogram of males and females on Day 1 (pre-exposure) (a), Day 2 (conditioning)

414 (b) and Day 3 (conditioning) (c) illustrating the onset and duration of behaviors over trials in 415 seconds. Legend differentiates recorded behaviors.

416 Figure 5. Changes in adaptive behaviors in the conditioned flight paradigm. Comparison of 417 adaptive behaviors like rearing $(\mathbf{a}, \mathbf{d})$, grooming $(\mathbf{b}, \mathbf{e})$, and tail rattling $(\mathbf{c}, \mathbf{f})$ in males and females 418 over all the experimental sessions of the conditioned flight paradigm. The represented values are

419 means \pm SEM. Mixed-effects analysis, effect of session ${ }^{*} p<0.05,{ }^{* *} p<0.01,{ }^{* * *} p<0.001 ;{ }^{\#} p<0.05$ 420 male vs female. Mann-Whitney test, ${ }^{\$} p<0.05$. 
bioRxiv preprint doi: https://doi.org/10.1101/2019.12.20.885038; this version posted December 23, 2019. The copyright holder for this preprint (which was not certified by peer review) is the author/funder, who has granted bioRxiv a license to display the preprint in perpetuity. It is made available under aCC-BY-NC-ND 4.0 International license.

Figure 1: The conditioned flight paradigm

a Day 1

Day 2

Day 3

Day 4

\section{$4 \times$ SCS}

$5 \times$ SCS-US $5 \times$ SCS-US

$16 \times \operatorname{scs}$

Pre-exposure

Fear conditioning

Extinction

b SCS

US

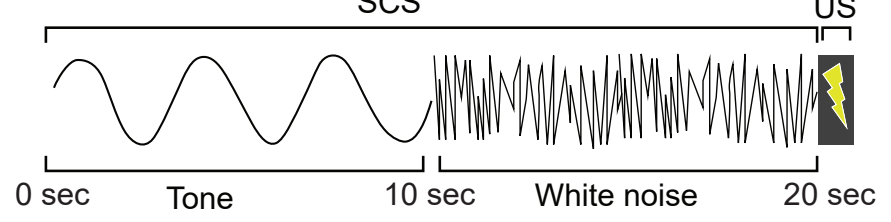


bioRxiv preprint doi: https://doi.org/10.1101/2019.12.20.885038; this version posted December 23, 2019. The copyright holder for this preprint (which was not certified by peer review) is the author/funder, who has granted bioRxiv a license to display the preprint in perpetuity. It is made available under aCC-BY-NC-ND 4.0 International license.

Figure 2: Sex differences in the conditioned flight paradigm
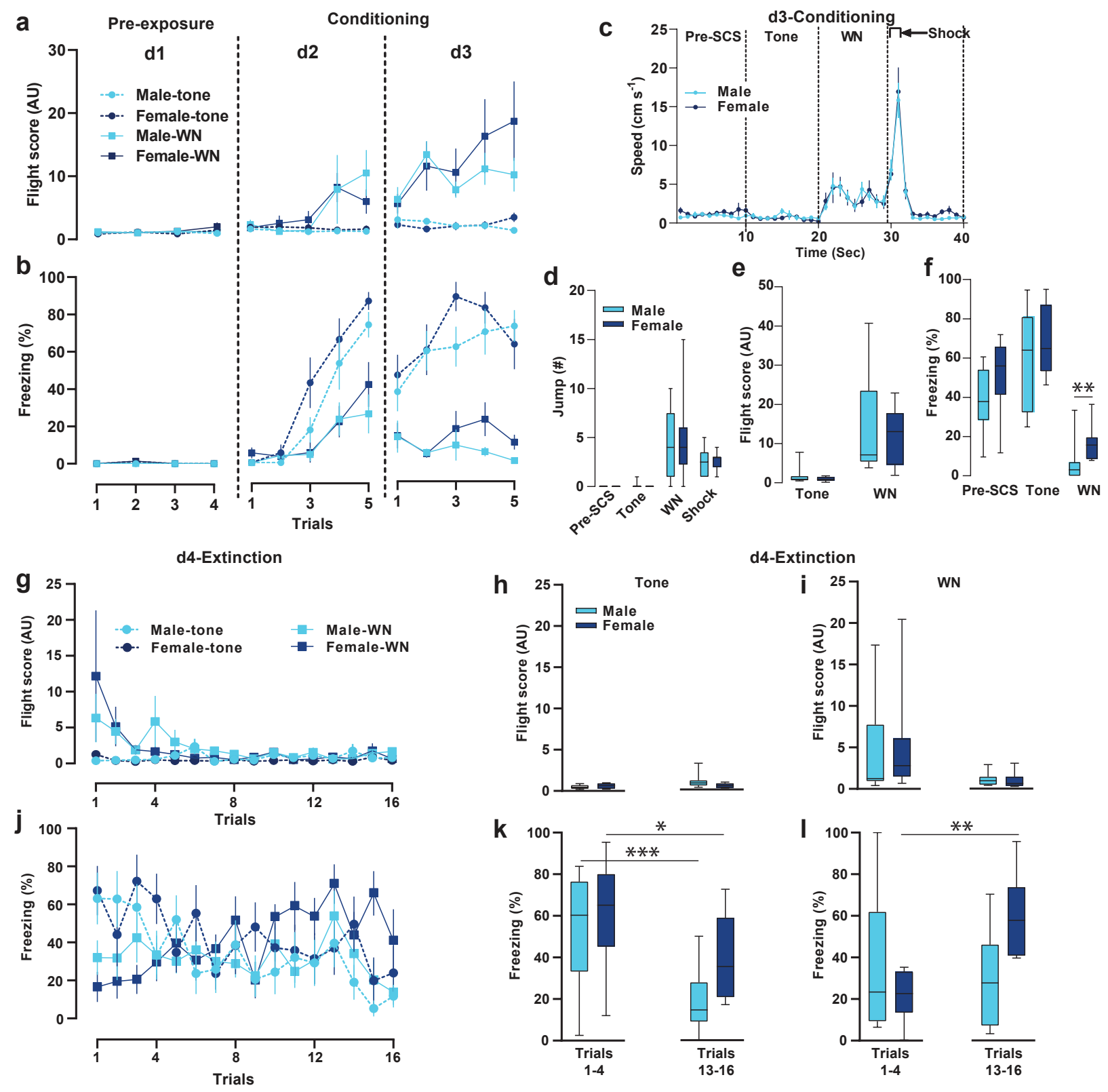
a

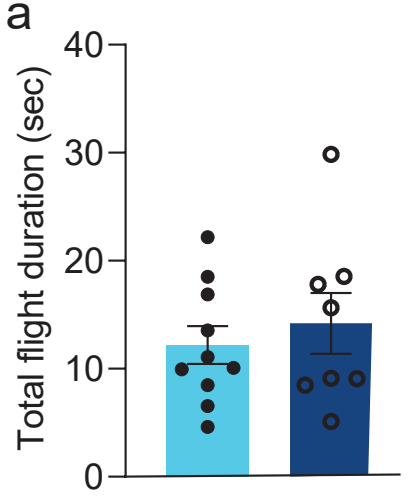

$\mathrm{d}$
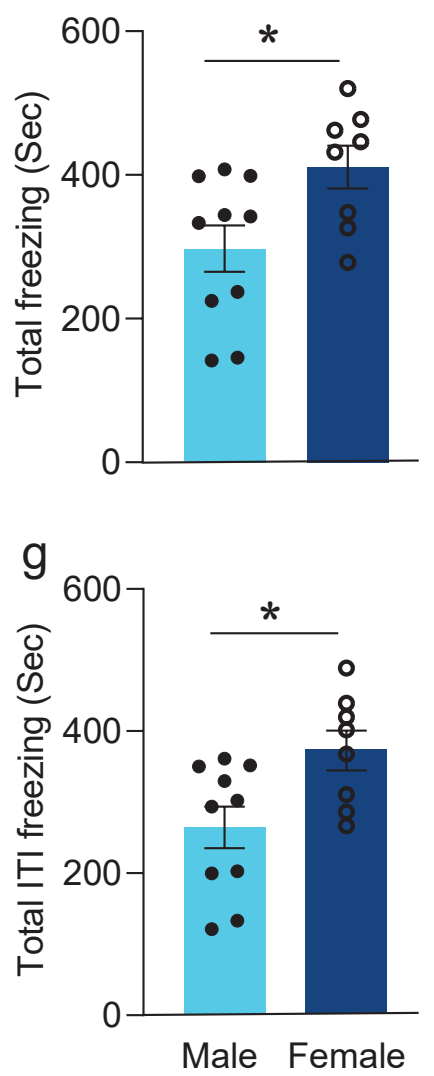

b

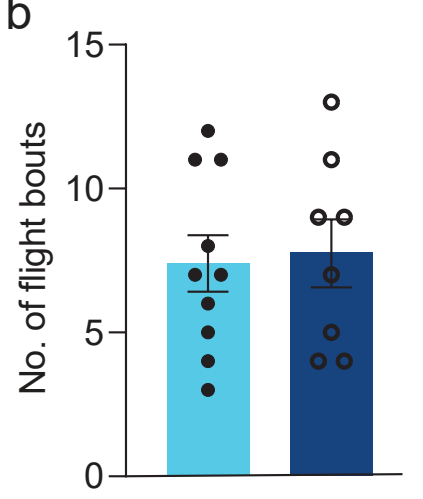

e

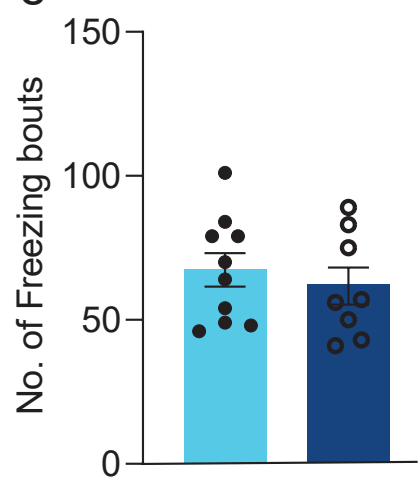

h

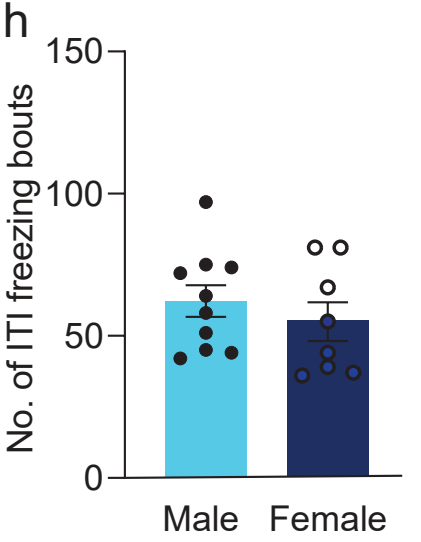

C

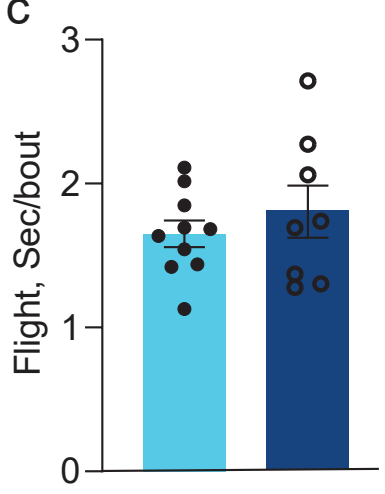

f

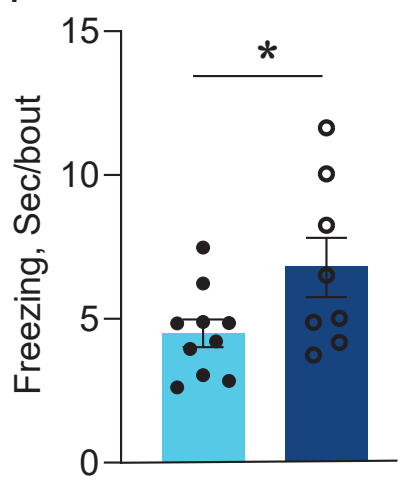

i

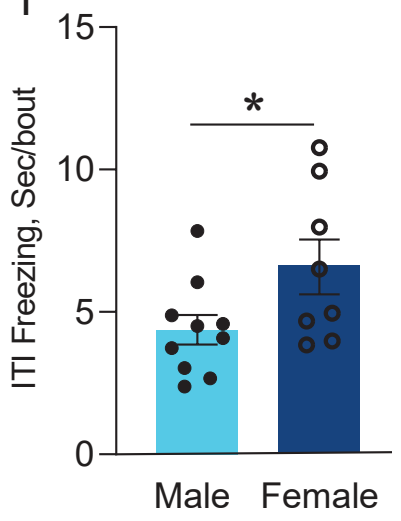




\section{Exploration Freezing Elight Grooming IRearing @ Jump \# Tail Rattling}
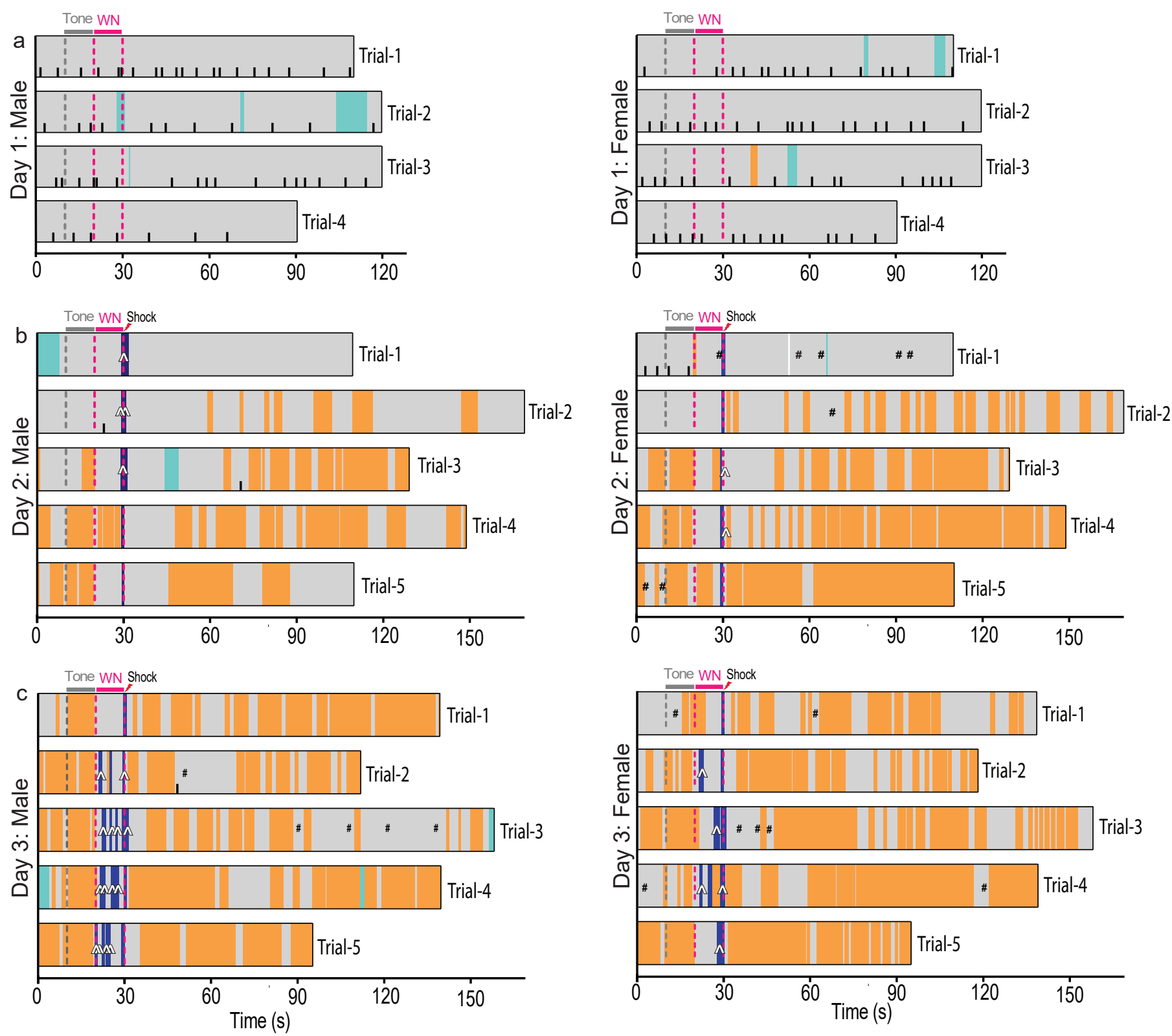
bioRxiv preprint doi: https://doi.org/10.1101/2019.12.20.885038; this version posted December 23, 2019. The copyright holder for this preprint (which was not certified by peer review) is the author/funder, who has granted bioRxiv a license to display the preprint in perpetuity. It is made available under aCC-BY-NC-ND 4.0 International license.

Figure 5: Changes in adaptive behaviors in the conditioned flight paradigm
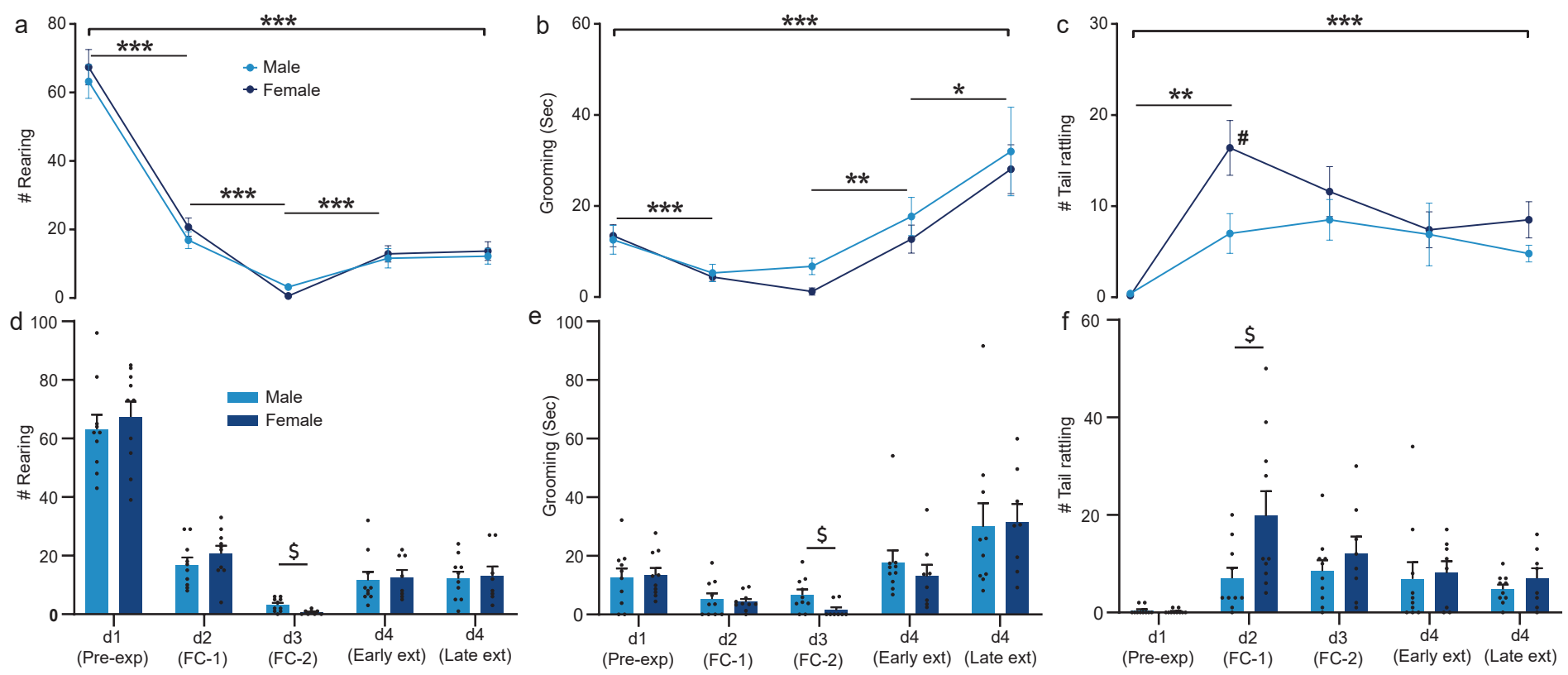